\title{
Sara Arber and Virpi Timonen (eds.) (2012). Contemporary Grandparenting. Changing Family Relationships in Global Contexts. Bristol, UK: The Policy Press, 270 pp. ISBN 978184742 9674 (paperback)
}

\author{
RevieWed by PegGy EDWARds*
}

This edited volume provides an excellent addition to our understanding of contemporary grandparenting in diverse welfare stares and cultural contexts. It is not quite as global in scope as the title suggests but provides informative analyses from studies of grandparenting in rural China, the United States, Hong Kong, Norway, Singapore, the United Kingdom, Ireland, Portugal and Germany, as well as cross-references and summaries of findings from other developed regions of the world. The inclusion of a variety of countries highlights the reality that while grandparenting has some universal similarities, the forms and intensities and the lived experience of grandparenting differ markedly among various societal and cultural contexts. The editors were right to constrain the focus to the developed world - at 270 pages (including an Introduction, Conclusion and Index), the book could not have extended itself further. However, I found myself wanting to read about contemporary grandparenting in Africa and other developing regions where grandparents play particularly critical roles in raising orphaned grandchildren and in the economic and

* Peggy Edwards, Grandmothers Advocacy Network, Ottawa, Canada 
International Journal of Ageing and Later Life

social future of their communities. Interesting perspectives, perhaps for a future book.

This book considers "grandparenting" as an active, dynamic family practice with an emphasis on the why's and how's of "doing" grandparenting. Underlying this are the fundamental societal changes that shape the practices of grandparenting, including demographic changes (increases in longevity, declines in fertility and changes patterns of marriage, divorce and cohabitation) and changes in labour force participation (increased employment of women outside the home, migratory flows for paid employment, domestic workers in families and the effects of both early and delayed retirement).

Alongside these macro-level changes, public policies, socioeconomic inequalities and cultural contracts within any society play a profound role in influencing interpersonal relationships and roles within families. For example, where there is public provision of high-quality daycare (e.g. in Scandinavian countries), grandparents may not be constrained by daily grandchild care. While the employment of foreign domestic workers may be a solution to support mothers' paid work in mid- and high-income families in Singapore (Chapter 6), the domestic workers themselves may have left behind children and grandchildren in their native countries. In rural China, grandchild caring may be perceived as part of a social contract wherein money comes back to grandparent caregivers, thus elevating the economic and social status of the whole family.

The editors begin with an Introduction that overviews some known concepts and theoretical frameworks of grandparenting that are further advanced in the chapters to come, and suggest that these chapters will also provide new insights, including how grandparents themselves exert an influence on their role in diverse settings. Successive chapters are divided into two parts.

Part One, which is macro-focussed, explores grandparents' responses to modern economic, societal and family transformations. Structures, public policies and socioeconomic status have a critical influence on grandparenting practices and agency. For example, in societies with little public support for parents with young children, extensive and regular childcare by grandparents is often essential in enabling mothers to be active in the workplace ("mother savers"). In societies with welfare policies that reduce 
the work-family conflict, grandparents frequently serve a "family-saver" function by being available when extra support and help are needed. Although the "mother-saver" role generally includes childrearing, it differs considerably from the "child-saver" role, when grandparents take on a fulltime parenting role without the presence of the middle generation.

Part Two focusses on grandparent identities and agency, which are micro-level constructs that are nonetheless powerfully shaped by macrolevel influences. Key concepts examined are the almost universal norms of obligation and non-interference, and the ambivalence that arises with these norms. Grandparents' belief that they should not interfere with adult children's parenting is complicated by their wish to instruct them, and their concerns about the education and behaviour of their grandchildren. Another competing ideal concerns the commitment to "being there" for grandchild care as needed, and the values of personal independence and self-determination. Grandparents who are heavily involved in looking after grandchildren may not be able to actualize the increasingly prevalent ideals of doing what they want to do in retirement and to their own selfactualization, a key facet in healthy, active ageing.

As someone with an interest in grandparenting from a contemporary perspective and as a grandmother myself, I was pleased to see that the editors have ensured that the book consistently addresses both a gendered perspective and a three-generational approach. In reality and as shown by most of the case studies in this book, the term "grandparenting" most often reflects the care and support provided by grandmothers. However, men's roles and identities as grandfathers are insufficiently explored in the social science literature, reflecting a failure to take into account contemporary factors such as the emergence of more nurturing identities among fathers and grandfathers in this generation, as well as how new communication technologies enable grandfathers to interact with their grandchildren. In Chapter 9, Anna Tarrant shows that grandfathers' engagement with their grandchildren is primarily influenced by relationships with the middle generation and particularly by divorce in the family. She proposes that there is a need for a redefinition of grandfather identities and masculinities based on a framework that takes the intersection of gender, intergenerational relationships and changing family circumstances into account. 
International Journal of Ageing and Later Life

Several chapters explore the agency of each party within the intergenerational triad. In a refreshing look at "grandchilding" practices, Chapter 10 describes how adolescent grandchildren influence their emotionally closest grandparent. Gender and the intergenerational triad are intertwined - the gender of the grandparent, the grandchild and the middle generation all influence grandparenting practices.

Contemporary Grandparenting is primarily based on revised versions of papers presented at the International Sociological Association conference held in Sweden in 2010. The 18 contributors have impressive credentials, and editors Arber and Timonen have done an excellent job in establishing themes that set their research into a readable, thoughtful volume. Not surprisingly, they also suggest compelling ideas and topics for future research. 